\title{
Volatility Estimation using Extreme-Value- Estimators \& MLP Model
}

\author{
Dr. J. K. Mantri \\ Deptt. of Comp. Sc \& Applications \\ North Orissa University, Orissa
}

\author{
Prof.P.Gahan \\ Deptt. Of Business Administrations \\ Sambalpur University
}

\begin{abstract}
Neural networks are the artificial intelligence techniques for modeling complex target functions. Now-a-days it has made remarkable contributions to advancement of various field of finance such as time series prediction, volatility estimation etc. The present work examines the volatilities in the Indian stock market (BSE-SENSEX \& NSE-NIFTY) by comparing the volatilities, using Parkinson method, Roger Schell model, German Klass \& ANN models. The work concludes that, there is no difference between the models in arriving at volatility in both the indices.
\end{abstract}

\section{Keywords}

Parkinson model, German Klass model, Roger Schell model, MLP.

\section{INTRODUCTION}

The stock market volatility and liquidity play important roles in the context of investment strategy for risk management, derivative pricing, hedging of systematic risk, optimal portfolio selection and monetary policy formulation. The importance of emerging markets including India in the world at large has received considerable attention of the foreign institutional investors (FIIs), domestic investors, mutual funds, and hedge funds, companies in the private corporate sector and the Government in recent years.

Though, the research interest in volatility of financial assets has dated back to the early sixties, the techniques. [6] for volatility modeling and forecasting have attracted attention of researchers, financial analysts, financial consultants, investors and mutual funds in recent years. Recognizing the stylized facts like clustering, asymmetry and persistence of the financial data carries correct volatility estimates. These are highly essential in order to ascertain accurate option valuation; construct optimal portfolio of financial assets; hedge systematic risk; and linearly evaluate the performance of the portfolios. The models used by Parkinson (1980), Garman and Klass (1980), and Rogers, Satcell(1991) are most useful estimators among all to calculate the stock market volatility..

But the Artificial Neuron Networks (ANNs) model is superior to economic models in calculating \& forecasting stock market volatility, as they have the ability to analyze complex patterns quickly \& with a high degree of accuracy. Secondly ANNs make no assumptions about the nature of the distribution of the data. They are not, therefore, biased in their analysis. Consequently, better results can be expected with neural networks when the relationship between the variables does not fit an assumed model. Third, since time-series data are dynamic in nature, it is necessary to have non-linear tools in order to discern the time - series relationship [8]. Fourth, neural networks perform well with missing or incomplete data. Where as traditional regression analysis is not adaptive, indiscriminately processing older data together with new data. Fifth, compared with an econometric model, it is easier for ANNs where a forecast needs to be obtained in a shorter period of time.

Since economic, financial \& social systems are complex \& subject to human reactions \& counter-reactions by different agents or players, it is difficult, if not impossible, to write down a complete model with all the potential reactions \& counterreactions. In such complex systems, it is natural to turn to models, which emulate $\&$ simulate the economy or the society in question. That is exactly what the neural network methodology is capable of delivering. For example, this capability of neural networks in modeling linear time series has been studied and confirmed by number of researchers [1], [2],[4],[7] \&[11],

Here we have compared the volatilities observed from MLP (Multilayer Perceptron) of Artificial Neural Network with that of Extreme-value Volatility Estimators -Parkinson Garman and Klass (1980), and Rogers, Satcell(1991),for Indian stock market indices -Bombay Stock Exchange Sensitivity i.e BSE Sensex containing 30 shares \& National stock Exchange-S\&P CNX Nifty containing 50 shares from 2005 to 2010 .

\section{METHODOLOGY}

\section{Extreme-Value Volatility Estimators}

Parkinson (1980) was the first to suggest the following estimator based on the highest and the lowest prices observed in a day, i.e., the trading range.

$$
\sigma_{P V}=k . s q r t\left(\frac{1}{n} \sum \operatorname{In}\left(\frac{H_{t}}{L_{t}}\right)^{2}\right.
$$

Where, $\mathrm{k}=0.601$ or $\mathrm{k}=1, \mathrm{Ht}=$ Intraday High Price, $\mathrm{Lt}$ $=$ Intraday Low Price

$$
\mathrm{n}=\text { no. of observations, } \sigma_{\mathrm{PV}}=\text { Volatility of return as }
$$

per Parkinson

The unbiased estimator Garman and Klass (1980) with superior efficiency extended Parkinson's work to include the opening and closing prices along with high and low prices in a trading day. Accordingly, they propose the model of volatility presented as

$$
\sigma_{G K V}=\sqrt{\frac{1}{n} \sum\left[0.5\left[\operatorname{In}\left(H_{t} / L_{t}\right)\right]^{2}-2 \operatorname{In}(2)-1\left[\operatorname{In}\left(C_{t} / O_{t}\right)\right]^{2}\right]}
$$

Where, $\mathrm{n}=$ No. of observations $, \mathrm{H}_{\mathrm{t}}, \mathrm{L}_{\mathrm{t}}, \mathrm{C}_{\mathrm{t}}$, and $\mathrm{O}_{\mathrm{t}}$ denote intraday high, low, close and open values respectively. $\sigma$ GKV $=$ Volatility of return on per German and Klass (1980) 
Roger and Satchell (1991) suggested yet another, more robust, volatility estimator that, unlike the two other estimators described above, does not assume a drift less Geometric Brownian motion of the prices between two points of observation. Their estimator is as follows:

$$
\sigma_{R S V}=\sqrt{\frac{1}{n} \sum\left[\left[\operatorname{In}\left(H_{t} / C_{t}\right)\right]\left[\operatorname{In}\left(H_{t} / O_{t}\right)\right]+\left[\operatorname{In}\left(\frac{L_{t}}{C_{t}}\right)\right]\left[\operatorname{In}\left(C_{t} / O_{t}\right)\right]\right]}
$$

Where, $\sigma_{G K V}=$ Volatility of return as per Roger and Satchell (1991)

\section{The Multilayer Perceptron Model}

The multilayer perceptron models (MLPs), feed forward Neural Network is the most useful applications of neural networks to data analysis. MLPs are nonlinear neural network models that can be used to approximate almost any function with a high degree of accuracy [13]. It contains input, hidden \& output layers. But the number of inputs and outputs in the MLP, as well as the number of hidden layers, can be manipulated to analyze different types of data. Figure 1 presents a multi layer perceptron with multiple inputs and outputs.



Figure 1 Multi-layer Perceptron with Multiple inputs and outputs

The MLP shown in this figure also represents multivariate multiple nonlinear regression. The complexity of the MLP can be adjusted by varying the amount of hidden layers, thus, transforming an MLP from a simple parametric model to a flexible non-parametric model. An MLP consisting of only one layer is very close to the projection pursuit regression model, which allows computation of explicit formulae for bias and error about the mean in orientation estimates and curve estimates

\section{ANALYSIS OF RESULTS}

Table 1 represents the year wise daily extreme value volatility estimations by using intraday price like opening, high, low \& closing with help of Parkinson, German \& Klass and Roger \& Satchell models of Indian stock market (Sensex and Nifty) from 2005 to 2010.

TABLE 1: Daily volatility of BSE Sensex \& Nifty for the period 2005-2010

\begin{tabular}{|l|l|l|}
\hline & SENSEX & NIFTY \\
\hline
\end{tabular}

\begin{tabular}{|c|c|c|c|c|c|c|}
\cline { 2 - 5 } Year & $\begin{array}{l}\text { PKV } \\
(\%)\end{array}$ & $\begin{array}{l}\text { RSV } \\
(\%)\end{array}$ & $\begin{array}{l}\text { GKV } \\
(\%)\end{array}$ & $\begin{array}{l}\text { PKV } \\
(\%)\end{array}$ & $\begin{array}{l}\text { RSV } \\
(\%)\end{array}$ & $\begin{array}{l}\text { GKV } \\
(\%)\end{array}$ \\
\hline 2005 & 0.977 & 0.946 & 0.957 & 1.085 & 1.047 & 1.068 \\
\hline 2006 & 1.459 & 1.433 & 1.423 & 1.612 & 1.596 & 1.592 \\
\hline 2007 & 1.254 & 1.191 & 1.215 & 1.515 & 1.506 & 1.478 \\
\hline 2008 & 2.231 & 2.175 & 2.158 & 2.626 & 2.632 & 2.541 \\
\hline 2009 & 1.585 & 1.429 & 1.491 & 1.847 & 1.66 & 1.723 \\
\hline 2010 & 0.937 & 0.907 & 0.903 & 1.003 & 0.952 & 0.966 \\
\hline
\end{tabular}

PKV: Volatility through Parkinson Model which uses high and low prices

RSV: Volatility through Roger and Satchell Model which uses high, low, opening and closing prices

GKV: Volatility through German and Klass Model which uses high, low, opening and closing prices

From 2005 to 2010 , it is found that volatility from German Klass model has a downward bias as compared to Parkinson volatility and volatility from Roger Satchell model is more downward than the volatility from other models. But in case of $2009 \& 2010$ it is observed that the volatility is moderate.

Table 2 Daily Volatility of Sensex and Nifty under MLP Technique of ANNs Model ( In \% )

\begin{tabular}{|c|r|r|}
\hline & \multicolumn{1}{|c|}{ SENSEX } & \multicolumn{1}{c|}{ NIFTY } \\
\hline YEAR & MISO & MISO \\
\hline 2005 & 0.95566 & 0.96189 \\
\hline 2006 & 1.25608 & 1.29434 \\
\hline 2007 & 1.47939 & 1.42525 \\
\hline 2008 & 2.51065 & 2.34098 \\
\hline 2009 & 1.382275 & 1.55666 \\
\hline 2010 & 0.844837 & 0.799465 \\
\hline
\end{tabular}

NB: MISO: Multiple Inputs Single Output.

Table 2 represents volatilities in percent under multiple inputs as opening; high and low index levels and single output as the closing index level through the MLP of ANNs in case of Sensex $\&$ Nifty. Similarly Table 3 shows the daily volatility under ANNs model and other models like Parkinson (1980), German-Klass (1990), Roger-Satchell (1991) year over 2005 to 2010 of Sensex.

Table 3 Year wise Daily volatility of Sensex under Parkinson, German-Klass Roger-Satchell and ANN models ( in \% )

\begin{tabular}{|c|c|c|c|c|}
\hline $\begin{array}{c}\text { Yea } \\
\mathbf{r}\end{array}$ & $\begin{array}{l}\text { Volatility } \\
\text { ANNs(MISO } \\
\text { ) }\end{array}$ & $\begin{array}{l}\text { Volatility } \\
\text { PK } \\
\end{array}$ & $\begin{array}{l}\text { Volatility } \\
\text { GK } \\
\end{array}$ & $\begin{array}{l}\text { Volatility } \\
\text { RS } \\
\end{array}$ \\
\hline 2005 & 0.956 & 0.977 & 0.957 & 0.946 \\
\hline 2006 & 1.256 & 1.459 & 1.423 & 1.433 \\
\hline 2007 & 1.479 & 1.254 & 1.215 & 1.191 \\
\hline 2008 & 2.511 & 2.231 & 2.158 & 2.175 \\
\hline 2009 & 1.382 & 1.585 & 1.491 & 1.429 \\
\hline 2010 & 0.844 & 0.937 & 0.903 & 0.907 \\
\hline
\end{tabular}

NB: PK: Parkinson Model, GK: German-Klass Model, RS: Roger-Satchell Model.

It has been observed that volatility under Parkinsons model, which considers extreme values like high and low of the index in 
a day, is higher than that of the ANN volatility. Volatility calculated under German -Klass model by considering high, low, opening and closing is mostly less than that of ANN model in most of the years. Similar conclusions are also made by comparing volatility under ANN model with that of the Roger Satchell model. Now whether statistically there is difference or not in the volatilities estimated under difference models is tested by using the Analysis of Variance (ANOVA) test.

Table 4: Sensex Volatility under one way ANOVA

\begin{tabular}{|c|c|c|c|c|c|c|}
\hline \multicolumn{7}{|c|}{$\begin{array}{l}\text { Arota: Sirgle Facta } \\
\text { SUMLMARY }\end{array}$} \\
\hline Grougs & Count & Sum & AverneF & $p_{b}$ rimale & & \\
\hline MUS0 & 6 & 8.428 & 1.404667 & 035553 & & \\
\hline PK & 6 & 8.443 & 1.407167 & 0228515 & & \\
\hline GK & 6 & 8.147 & 1357833 & 0210038 & & \\
\hline $\mathrm{RS}$ & 6 & 8,081 & 1346833 & 0215688 & & \\
\hline $\begin{array}{l}\text { AHOVA } \\
\text { Source of } \\
\mathrm{V}_{\text {Wintion }}\end{array}$ & $S$ & $\phi$ & $M N$ & $F$ & P-wolue & Fø̈ं \\
\hline $\begin{array}{l}\text { Between } \\
\text { Grams } \\
\text { Wtrin }\end{array}$ & 0017609 & 3 & 0.0587 & 0023297 & 0995025 & 3098391 \\
\hline Groms & 5038966 & 20 & 0251948 & & & \\
\hline Tatol & 5056575 & 23 & & & & \\
\hline
\end{tabular}

Table 4 shows One-Way ANOVA results of Sensex Volatility under Parkinson, German-Klass Roger-Satchell and ANN models. Here the calculated value of ' $F$ ' is less than the critical value of ' $F$ ' at $23 \%$ significance level. Hence, it is concluded that there is no difference between the methods in arriving at volatility which is graphically represented in fig 2 . But table 5 presents the volatility of Nifty under ANN, Parkinson, German Klass and Roger -Satchell models.

Table 5: Year wise Daily volatility of Nifty under Parkinson, German-Klass Roger-Satchell and ANN models ( in \% )

\begin{tabular}{|c|c|c|c|c|}
\hline $\begin{array}{c}\text { Yea } \\
\mathbf{r}\end{array}$ & $\begin{array}{c}\text { Volatility } \\
\text { ANNs(MISO } \\
\text { ) }\end{array}$ & $\begin{array}{c}\text { Volatility } \\
\text { PK }\end{array}$ & $\begin{array}{c}\text { Volatility } \\
\text { GK }\end{array}$ & $\begin{array}{c}\text { Volatilit } \\
\mathbf{y} \\
\text { RS }\end{array}$ \\
\hline 2005 & 0.962 & 1.085 & 1.068 & 1.047 \\
\hline 2006 & 1.294 & 1.612 & 1.592 & 1.596 \\
\hline 2007 & 1.425 & 1.515 & 1.478 & 1.506 \\
\hline 2008 & 2.341 & 2.626 & 2.541 & 2.632 \\
\hline 2009 & 1.557 & 1.847 & 1.723 & 1.66 \\
\hline 2010 & 0.799 & 1.003 & 0.966 & 0.952 \\
\hline
\end{tabular}

Similar results are also obtained in case of Nifty like that of Sensex. Volatility calculated under Parkinson formulae is less than that of ANN model in most of the years. It is also observed that the volatilities under German Klass and Roger - Satchell are less than the volatility of ANN model. Whether, actually there are differences in the volatilities between different models or not, ANOVA (Analysis of Variance) test is applied to arrive at the conclusion of difference statistically.
Table 6: Nifty volatily under one-way ANOVA

\begin{tabular}{|c|c|c|c|c|c|c|}
\hline \multicolumn{5}{|c|}{$\begin{array}{l}\text { Anova: Single Factor } \\
\text { SUMMARY }\end{array}$} & & \\
\hline Goups & Count & Sum & Average & Variance & & \\
\hline MISO & 6 & 8.378 & 1.396333 & 0.294991 & & \\
\hline PK & 6 & 9.688 & 1.614667 & 0.348279 & & \\
\hline $\mathrm{GK}$ & 6 & 9.368 & 1.561333 & 0.318313 & & \\
\hline RS & 6 & 9.393 & 1.5655 & 0.359209 & & \\
\hline \multicolumn{7}{|l|}{ ANOVA } \\
\hline $\begin{array}{l}\text { Sounce of } \\
\text { Variation } \\
\text { Between }\end{array}$ & $S S$ & of & MS & $F$ & P-lake & $F$ crit \\
\hline $\begin{array}{l}\text { Groups } \\
\text { Uúthin }\end{array}$ & 0.163186 & 3 & 0.054395 & 0.164736 & 0.918862 & 3098391 \\
\hline Groups & 6.603968 & 20 & 0.330198 & & & \\
\hline Total & 6.767154 & 23 & & & & \\
\hline
\end{tabular}

Table 6 shows one way ANOVA results of Nifty Volatility under Parkinson, German-Klass Roger-Satchell and ANN models. From the ANOVA result, it is observed that the calculated value of ' $F$ ' is less than the critical value of ' $F$ '. In other words, it can be interpreted that there is no significant difference in the volatilities estimated under ANN model and other models like Parkinson (1980), German-Klass (1980), Roger-Satchell (1991) which is represented in fig3.

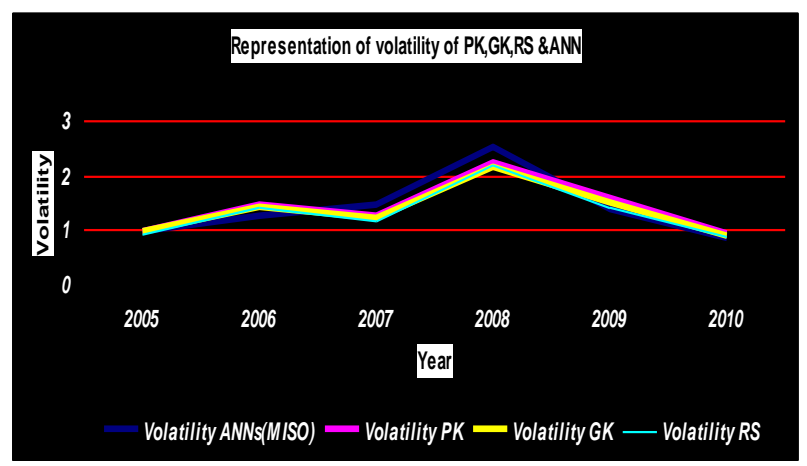

Fig.2 Graphical representation of volatility of BSE Sensex used by Parkinson,German Klass, Roger Satchell \& ANN model

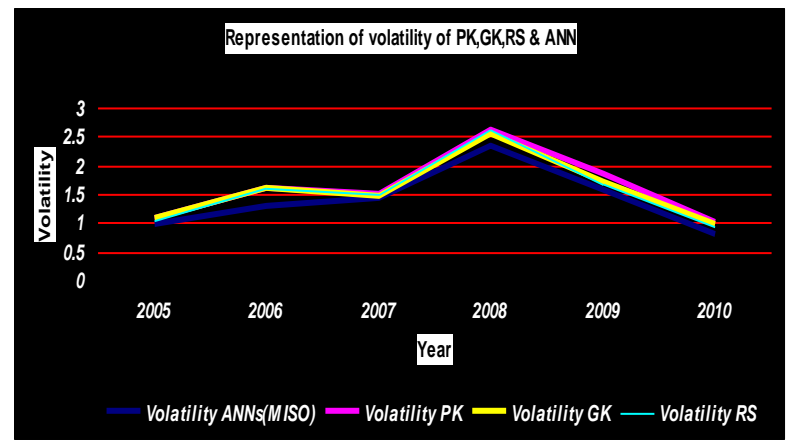

Fig.3 Graphical representation of volatility of NSE Nifty used by Parkinson,German Klass, Roger Satchell \& ANN model 


\section{CONCLUSION}

Volatility forecasting is a important area of research in Fancial Market as because correct volatility estimation helps in hedging of risk, portfolio construction, option pricing \& performance evaluation etc.In this article we have estimated the volatility for Indian Stock market by considering Sensitivity Index \& NSE Nifty (using the daily return data from 2005 to 2010) with the help of various estimators like Parkinson,Roger Schell \& German Klass \& MLP (ANN)..MLP model is mainly used in extract non-linear regularities for economic time series \& there by decode previously undetected regularities in ascertain price movements, such as fluctuation of stock prices [12].It also significantly out perform further regression model.

From the analysis of variance test, it is concluded that there is no difference in arriving at volatility in both the indices (Sensex \& Nifty) by using Parkinson model, Roger Schell model, German Klass model of Finance with that of MLP model of Artificial Neural Network. Even though modeling techniques are rapidly changing and improving day by day, the traders, financial analysts and economists can use any method safely to estimate the volatility. As a future work, we recommend to use hybrid approaches, which are a combination of ANN with other techniques like, Fuzzy logic, Genetic Algorithm for the volatility estimation of Stock Market.

\section{REFERENCES}

[1] Andrade, Chang, Tabak (2003) Tracking Brazilian Exchange Rate Volatility, Econometric Society 2004 Far Eastern Meetings, 1-27

[2] Eckner, A., Horel, G., Saita, L., (2006) Frailty correlated default. Working paper, Stanford University

[3] German M. \& Klass M. (1980) "On the Estimation of security Price volatility from historical data" journal of business, Vol53, 67-69.

[4] Gemmill, G., (1996), "Transparency and liquidity: A study of block trades in the London Stock Exchange under different publication rules", Journal of Finance 51, 17651790
[5] Kunitomo, N. (1992) Improving the Parkinson method of estimating security price volatilities, Journal of Business, 65, 295-302.

[6] Mandelbrot, B. (1963), 'The Variation of Certain Speculative Prices', Journal of Business 36(3), 394-419

[7] Mantri J.K., Gahan P. \& Nayak B.B.(2010) "Artificial Neural Network -An Application to Stock Market Volatility, IJEST, Vol. 2(5), 2010, 1451-1460

[8] Maasoumi E., A. Khotanzad, and A. Abaye, (1994), "Artificial Neural Networks for some Macroeconomic Series : A First Report,” Econometric Reviews,13(1),105-22

[9] Parkinson, (1980) "The extreme value method for Estimating the variance of the rate of Return", Journal Business, Vol.53, 61-65

[10] Roger, L CG, Satchell, SE (1991) “ Estimating variance from High, Opening \& Closing Price annals of applied probability, 1(4),504-512

[11] Sarle, W.S., 1994, "Neural Networks and Statistical Models," Proceedings of the Nineteenth Annual SAS Users Group International Conference, Cary, NC: SAS Institute, April, 1538-1550

[12] Torous, Walter, Ross Valkanov, and Shu Yan, 2004, "On predicting stock returns with nearly integrated explanatory variables," Journal of Business 77, 937-966

[13] White, H., 1992, Artificial Neural Networks: Approximation and Learning Theory, With A. R. Gallant, Cambridge and Oxford: Blackwell. 